\title{
Systematischer Index
}

Subfam. Saginae . . . . . 13

1. Genus Clonia . . . . . . . 16

I. Subgenus Clonia s. str. . . 16

1. C. (C.) multispina . 19

2. C. (C.) zernyi . . . 21

3. C. (C.) wahlbergi . 21

3a. C. (C.) w. wahlbergi . . . 21

3b. C. (C.) w. maculosa ... 23

4. C. (C.) saussurei. . 23

5. C. (C.) intermedia . 24

6. C. (C.) kalahariensis 25

7. C. (C.) caudata . . 26

8. C. (C.) uvarovi . . 27

9. C. (C.) dewittei . . 28

10. C. (C.) burri . . . 29

11. C. (C.) jagoi . . . 31

12. C. (C.) kenyana . . 32

13. C. (C.) angolana. . 33

II. Subgenus Leptoclonia . . . 34

14. C. (L.) vittata . . . 35

15. C. (L.) vansoni . . 36

16. C. (L.) minuta. . . 37

III. Subgenus Xanthoclonia . . 38

17. C. (X.) tessellata. . 38

IV. Subgenus Hemiclonia . . . 41

18. C. (H.) melanoptera 42

19. C. (H.) lalandei . . 43

20. C. (H.) assimilis . . 44

21. C. (H.) charpentieri 45

22. C. (H.) ignota. . . 47
2. Genus Cloniella. . . . . 47

1. C. zambesica. . . . 49

2. C. praedatoria . . 49

3. Genus Saga . . . . . . 50

1. S. natoliae. . . . . 55

2. S. rhodiensis . . . . 56

3. S. ephippigera . . 57 3a. S. e. ephippigera 57

3b. S. e. syriaca . . 59

4. S. hellenica . . . 60

5. S. cappadocica . . . 61

6. S. rammei . . . . . 63

7. S. puella . . . . 63

8. S. campbelli . . . 65 8a. S. c. campbelli . 65

8b. S. c. gracilis . . 66

9. S. beieri . . . . 66

10. S. longicaudata. . . 67

11. S. ledereri. . . . . 68

12. S. ornata . . . . . 69

13. S. pedo . . . . . 70

4. Genus Peringueyella. . . 72

1. P. macrocephala . . 75

2. P. jocosa . . . . 75 2a. P. j. jocosa . . . 75

2b. P. j. multispina . 76

3. P. rentzi. . . . 76

4. P. zulu . . . . . 77

Incertae sedis . . . . . . 78

1. Saga quadrisignata .78

2. Saga savignyi . . 78

3. Saga uvarovi. . . . 78

4. Emptera indica . . 79 
